\title{
Molecular genetics of autosomal dominant retinitis pigmentosa (ADRP): a comprehensive study of 43 Italian families
}

\author{
C Ziviello*, F Simonelli*, F Testa, M Anastasi, S B Marzoli, B Falsini, D Ghiglione, C Macaluso, \\ M P Manitto, C Garrè, A Ciccodicola, E Rinaldi, S Banfi
}

J Med Genet 2005;42:e47 (http://www.jmedgenet.com/cgi/content/full/42/7/e47). doi: 10.1136/jmg.2005.031682

\begin{abstract}
Retinitis pigmentosa is the most common form of retinal degeneration and is heterogeneous both clinically and genetically. The autosomal dominant forms (ADRP) can be caused by mutations in 12 different genes. This report describes the first simultaneous mutation analysis of all the known ADRP genes in the same population, represented by 43 Italian families. This analysis allowed the identification of causative mutations in 12 of the families (28\% of the total). Seven different mutations were identified, two of which are novel (458delC and 6901C $\rightarrow$ T (P2301S), in the CRX and PRPF8 genes, respectively). Several novel polymorphisms leading to amino acid changes in the FSCN2, NRL, IMPDH1, and RPI genes were also identified. Analysis of gene prevalences indicates that the relative involvement of the RHO and the RDS genes in the pathogenesis of ADRP is less in Italy than in US and UK populations. As causative mutations were not found in over $70 \%$ of the families analysed, this study suggests the presence of further novel genes or sequence elements involved in the pathogenesis of ADRP.
\end{abstract}

$\mathrm{R}$ etinitis pigmentosa is a clinically and genetically heterogeneous type of retinal degeneration which results in progressive loss of vision. It is characterised by abnormalities of the photoreceptors or the retinal pigment epithelium. Patients with this disorder typically develop night blindness, followed by constriction of the peripheral visual fields, bone spicule-like pigmentary deposits, and abnormal electroretinography (ERG). In the more advanced stages of the disease, there are intraretinal and preretinal clumps of black melanin pigment, attenuated retinal vessels, loss of retinal pigment epithelium, and pallor of the optic nerve. ${ }^{1}$ The time of onset of the disease varies from childhood to middle age. ${ }^{2}$ The incidence is estimated to be 1 in $4000-5000$ people in Western populations. ${ }^{3}{ }^{4}$ Inheritance can be autosomal dominant, autosomal recessive, $\mathrm{X}$ linked, or in rare cases as a digenic trait. However, in the majority of cases (about 50$60 \%$ in the white population) it is impossible to establish the pattern of inheritance, and these cases are defined as "sporadic."

Autosomal dominant retinitis pigmentosa (ADRP) represents between $15 \%$ and $35 \%$ of all cases of the disorder, depending on the countries and the ethnic groups analysed, with the highest values being found in the USA ${ }^{8}$ and the lowest in southern Europe. ${ }^{9}$ A previous study reported that the prevalence of ADRP in the Italian population is about $17 \%,{ }^{10}$ which is concordant with estimates from other studies carried out in southern Europe. ${ }^{9}$ To date, 12 genes have been clearly associated with the pathogenesis of this condition (RETnet, http://www.sph.uth.tmc.edu/Retnet/disease.htm). The rhodopsin $(R H O)$ gene is the most commonly involved in ADRP (25-50\% of cases) followed by RPI (5-10\%), RDS (5\%), and IMPDHI (5-10\%). These prevalence values were all derived from different and heterogeneous studies mostly carried out in American and British populations, ${ }^{6}{ }^{11}{ }^{12}$ and a simultaneous analysis on all the 12 ADRP genes in a homogeneous population was never reported. In addition, fewer molecular studies have been carried out in non-British European patients with retinitis pigmentosa ${ }^{13}$ and no data at all are available for the Italian population.

Here, we describe the first comprehensive mutational analysis for all the currently known ADRP genes in the same population-that is, in a well characterised set of Italian ADRP families. We were able to detect causative mutations in approximately one third of the families analysed. The prevalences and the type of mutations identified indicate that the genetic epidemiology of ADRP in Italy, and possibly in southern Europe, is different from that reported in American and British populations.

\section{METHODS \\ Patients}

ADRP families were recruited from northern, central, and southern Italy. Informed consent was obtained from all adult subjects enrolled in the study. The six ophthalmological centres that participated in the study used the same protocols for the clinical diagnosis and the classification of patients. Only families showing a well defined autosomal pattern of inheritance were selected $(n=43)$-in particular those characterised by the presence of at least two affected generations and male to male transmission. The ophthalmological examination included the best corrected visual acuity with the Snellen visual chart, slit lamp biomicroscopy, fundus examination, Goldmann kinetic visual field examination, and electroretinography. The ERG was recorded by means of corneal contact lens electrodes with a Ganzfield stimulator according to international clinical standards.

\section{Mutation analyses}

Genomic DNA was extracted from blood samples employing standard techniques ${ }^{14}$ and amplified by polymerase chain reaction (PCR) using oligonucleotide primer pairs that amplify the coding exons as well as the intron-exon junctions of the ADRP genes selected for this study. The sequences of the primers and the PCR conditions were as previously described ${ }^{15-26}$ and are summarised in supplementary table 1, which can be viewed on the JMG website (http://

Abbreviations: ADRP, autosomal dominant retinitis pigmentosa; dHPLC, denaturing high performance liquid chromatography 
Table 1 Summary of autosomal dominant retinitis pigmentosa mutations identified

\begin{tabular}{lllllll}
\hline Gene & Nucleotide change & $\begin{array}{l}\text { Amino acid } \\
\text { change }\end{array}$ & Type of mutation & $\begin{array}{l}\text { Number of } \\
\text { families }\end{array}$ & $\begin{array}{l}\text { Relative } \\
\text { frequency }\end{array}$ \\
\hline$R P 1$ & $2029 \mathrm{C} \rightarrow \mathrm{T}$ & $\mathrm{R} 677 \mathrm{X}$ & Nonsense & 4 & 2 & $4.6 \%$ \\
$R H O$ & $403 \mathrm{C} \rightarrow \mathrm{T}$ & $\mathrm{R} 135 \mathrm{~W}$ & Missense & 2 & 4 & $9.3 \%$ \\
& $1040 \mathrm{C} \rightarrow \mathrm{T}$ & $\mathrm{P} 347 \mathrm{~L}$ & Missense & 5 & 2 & $4.6 \%$ \\
& $499 \mathrm{~T} \rightarrow \mathrm{C}$ & $\mathrm{C} 167 \mathrm{R}$ & & 2 & 1 & $2.3 \%$ \\
NRL & $152 \mathrm{C} \rightarrow \mathrm{T}$ & $\mathrm{P} 51 \mathrm{~L}$ & Missense & 2 & 1 & $2.3 \%$ \\
CRX & $458 \mathrm{delC}$ & $\mathrm{P} 153 \mathrm{fs}$ & Frameshift & 3 & 1 & $2.3 \%$ \\
PRPF8 & 6901C $\rightarrow \mathrm{T}$ & $\mathrm{P} 2301 \mathrm{~S}$ & Missense & 42 & 1 & $2.3 \%$ \\
\hline
\end{tabular}

www.jmedgenet.com/supplemental). In particular, we analysed all coding exons of the RHO, RDS, RPI, IMPDHI, PRPF31, CRX, NRL, FSCN2, HPRP3, and RP9 genes and the exons harbouring the previously identified mutations of the CA4 and PRPF8 genes, namely exons 1 and $42 .{ }^{23} 25$ This analysis was carried out in one patient per family. Amplified products underwent denaturing high performance liquid chromatography (dHPLC) analysis. All products displaying a dHPLC pattern different from controls were sequenced, using the ABI PRISM Big Dye terminator cycle sequencing V2.0 kit, and the reactions were analysed with an ABI-PRISM 3100 genetic analyser (Applied Biosystems, Foster City, California, USA). All the identified sequence variants leading to amino acid missense variations were first tested in the other members of the family, both affected and unaffected, to verify whether or not they segregated with the retinitis pigmentosa phenotype. If segregating with the disease, the sequence variants were also tested in at least 100 control chromosomes by DHPLC analysis. The CRX 458delC variation that led to a premature truncation of the CRX protein was not tested in control samples.

\section{RESULTS AND DISCUSSION}

\section{Family selection and clinical studies}

We selected for this analysis 43 Italian ADRP families (237 affected individuals in all) from a pool of about 600 families with retinitis pigmentosa. The age of disease onset in these cases ranged from 3 to 55 years (mean (SD), 15 (13.6) years; mean disease duration, 26.5 (15) years). The mean best corrected visual acuity was 20/50 (ranging from 20/20 to light perception). The ophthalmoscopic appearances were typical retinitis pigmentosa in $59.3 \%$ of cases, and atypical in $40.7 \%$ (no pigment, $4.8 \%$; sector involvement, $12.5 \%$; pericentral involvement, 3.3\%). Electroretinographic scotopic and photopic responses were extinguished in $71.6 \%$ of the patients, while a scotopic and photopic ERG was recordable in $11.5 \%$ and $16.9 \%$, respectively.

The non-biased geographical distribution of these families throughout Italy and a standardised clinical evaluation (see Methods) ensured that this sample was truly representative of the ADRP population in Italy. Based on previous reports, ${ }^{10}$ and on our preliminary data on the epidemiology of retinitis pigmentosa in Italy (unpublished data), we estimated that the prevalence of ADRP in Italy constitutes approximately $17 \%$ of the entire population of people with the disease. If we assume that the incidence of retinitis pigmentosa in Italy is $1 /$ 4000, the sample of ADRP patients recruited in this study should amount to about $10 \%$ of the entire Italian ADRP population and therefore represents a valid subset to assess the relative prevalences of the known retinitis pigmentosa genes in the pathogenesis of ADRP in Italy.

\section{Mutation analyses}

We carried out mutation analysis in the selected families on the 12 genes that have been clearly shown to be responsible for ADRP (see Methods and supplementary table 1). We identified the causative mutation in 12 of the 43 families analysed (28\%) (table 1). Overall, we detected seven different mutations, two of which represent new mutations. The RHO gene was mutated in seven families (16\% of cases), with three different mutations identified. The R135W missense mutation $(403 \mathrm{C} \rightarrow \mathrm{T}$ at the nucleotide level) represents the most frequent mutation in our set, as it was found in four families ( $9 \%$ of the total and $57 \%$ of all $R H O$ mutations). Two other mutations were found in more than one family, namely the RHO P347L and the RPl R677X (1040C $\rightarrow$ T and $2029 \mathrm{C} \rightarrow \mathrm{T}$, respectively, at the nucleotide level).

Two new mutations were identified in this study, one in $C R X$ and one in PRPF8. The novel CRX mutation was represented by the deletion of a cytosine at nucleotide position 458 (458delC) which leads to a premature truncation of the CRX protein at position 153 (P153fs). Patients harbouring this mutation have retinitis pigmentosa with macular dystrophy and extinguished ERG, which is consistent with the previously described ADRP phenotypes caused by $C R X$ mutations. ${ }^{11}{ }^{27}$ On the other hand, the novel PRPF8 mutation was a substitution of a cytosine with a timidine at nucleotide position $6901 \quad(6901 \mathrm{C} \rightarrow \mathrm{T})$ which leads to the substitution of the proline in position 2301 of the PRPF8 predicted protein with a serine (P2301S). This mutation represents the seventh missense mutation identified in the PRPF8 gene so far. This suggests that the nucleotide at position 6901 of the PRPF8 coding sequence is a sensitive site for mutations, as it was already found to be the target of an ADRP missense mutation by McKie et al (namely 6901C $\rightarrow$ A, leading to P2301T). ${ }^{28}$

As expected, the severity of the clinical phenotype in the families carrying the identified mutations could be related to the mutated gene. For example, in all the patients with $\mathrm{RHO}$ mutations, we observed a more severe phenotype. The patients had early onset of disease, retained central visual acuity until the second decade of life, had concentric isoptere shrinkage of up to $10^{\circ}$ in the centre at the Goldmann kinetic visual field examination, and had extinguished electroretinograms in the early stages of the disease. On the other hand-as also previously described ${ }^{15}$ - the clinical phenotype

Table 2 Novel single nucleotide polymorphisms leading to amino acid variations identified in autosomal dominant retinitis pigmentosa genes

\begin{tabular}{lll}
\hline Gene & Nucleotide change & Amino acid change \\
\hline IMPDH1 & $1142 \mathrm{~A} \rightarrow \mathrm{G}$ & $\mathrm{H} 381 \mathrm{R}$ \\
$\mathrm{NRL}$ & $199 \mathrm{C} \rightarrow \mathrm{T}$ & $\mathrm{P} 67 \mathrm{~S}$ \\
$\mathrm{FSCN} 2$ & $412 \mathrm{C} \rightarrow \mathrm{T}$ & $\mathrm{H} 138 \mathrm{Y}$ \\
$R P 1$ & $5448 \mathrm{C} \rightarrow \mathrm{A}$ & $\mathrm{C} 1816 \mathrm{X}$ \\
$R P 1$ & $1380 \mathrm{G} \rightarrow \mathrm{C}$ & $\mathrm{K} 460 \mathrm{~N}$ \\
$R P 1$ & $4735 \mathrm{~T} \rightarrow \mathrm{G}$ & $\mathrm{L} 1579 \mathrm{~V}$ \\
$R P 1$ & $1705 \mathrm{~A} \rightarrow \mathrm{G}$ & $\mathrm{T} 569 \mathrm{~A}$ \\
\hline
\end{tabular}


associated with $R P 1$ gene mutations was less severe with a late onset of disease, after the third decade of life. The patients retained good visual acuity and recordable rod and cone ERG signals until the start of the fourth decade.

\section{Identification of novel polymorphisms}

We also found novel single nucleotide polymorphisms in some of the genes analysed (RPI, IMPDH1, NRL, and FSCN2) that caused amino acid substitutions (table 2). In particular, the $R P 1$ gene has a significantly high frequency of missense variations with no pathogenic significance. Interestingly, one of these sequence variants, $5448 \mathrm{C} \rightarrow \mathrm{A}$, which determines a premature truncation of the RPl protein at amino acid position 1816 (C1816X), was found in the homozygous state in an unaffected relative of an ADRP patient. It was previously reported that premature truncations of the RPl protein in the C-terminal part (R1933X) were not involved in the retinitis pigmentosa pathogenesis. ${ }^{29}$ Our data not only extend to the amino acid position 1816 the $\mathrm{N}$-terminal border for non-pathogenic sequence variations in RPl but also suggest that most of the $340 \mathrm{C}$-terminal amino acids of this protein are not endowed with an important function, because their complete loss in homozygosity is apparently well tolerated and not associated with any abnormal phenotype. This hypothesis is also confirmed by the low conservation across evolution of this portion of the RPl protein. We also found sequence variations in the NRL, IMPDH1, and FSCN2 genes that lead to non-conservative amino acid variations and affect amino acids that are significantly conserved in evolution. However, none of these variants was found to segregate with the retinitis pigmentosa phenotype in the families analysed, indicating that they are polymorphisms and not causative of the retinitis pigmentosa mutation. In particular, the P67S sequence variant in NRL is of particular interest because it affects an amino acid residue that is highly conserved across evolution (it is present even in the chicken and in Xenopus laevis) and because of the very low occurrence of sequence variations in the $N R L$ gene. ${ }^{30}$ We did not detect this variation in more than 400 additional chromosomes analysed, suggesting that it is a rare polymorphism. It will be important to determine whether this sequence variation predisposes to retinitis pigmentosa or to other eye phenotypes.

\section{Relative gene prevalence in Italian ADRP}

The frequency of the involvement of the 12 genes analysed in these Italian ADRP families is reported in table 1 and fig 1 . As expected, RHO is the gene most commonly involved in ADRP pathogenesis, as causative mutations were found in $16 \%$ of families. However, this prevalence is less than the $25-50 \%$ range reported in the USA and the United Kingdom, ${ }^{11}{ }^{12}$ and

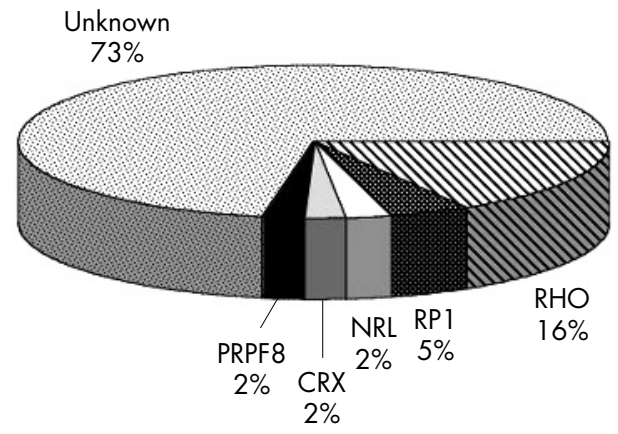

Figure 1 Classification of the families with autosomal dominant retinitis pigmentosa, based on the results of the mutation analyses. is more similar to that described in other populations from southern Europe-for example, Spain and southern France $^{13}{ }^{31}$-and in the Far East..$^{13} 3233$ The most common RHO mutation identified was the R135W (present in four families) followed by the P347L (in two families). On the other hand, the $\mathrm{P} 23 \mathrm{H}$ mutation, which is the most common one found in the USA, was not detected in our sample, and this is consistent with previous studies carried out in other European populations. ${ }^{34} 35$

Two families were mutated in the RPI gene, which therefore represents, after $R H O$, the gene most commonly responsible for ADRP in Italy. The other genes mutated in ADRP families were CRX, NRL, and PRPF8 (table 1). No mutations were detected in RDS, IMPDH1, and PRPF31, which together account for about $15 \%$ of ADRP in non-Italian populations (RETNET, http://www.sph.uth.tmc.edu/Retnet/ disease.htm). Altogether, these findings confirm that retinitis pigmentosa pathogenesis is very variable in different populations.

We did not identify causative mutations in any of the 12 ADRP genes screened in over $70 \%$ of the families analysed $(\mathrm{n}=31$; fig 1$)$. Thus the pathogenesis of the majority of ADRP families in Italy is not accounted for by mutations in the coding exons of the retinitis pigmentosa genes tested. We cannot exclude the possibility that the genes analysed in this report may nevertheless underlie retinitis pigmentosa pathogenesis in a fraction of these 31 Italian families owing to mutations residing in either unidentified exons or in regulatory elements of the analysed genes. However, our results strongly suggest the presence of additional unidentified genes that are involved in the pathogenesis of ADRP in these families, and extensive linkage analysis will be needed to discriminate between these two hypotheses.

We believe that this study, which is the first simultaneous and comprehensive clinical/molecular analysis of all the currently known ADRP genes in a well characterised set of families, will improve genetic counselling and the prognostic evaluation of retinitis pigmentosa in Italian patients, and shed further light on the molecular mechanisms underlying this complex group of disorder.

\section{ACKNOWLEDGEMENTS}

We wish to thank all the families who participated to this study. We thank Paolo Gasparini and Graciana Diez-Roux for critical reading of the manuscript and Giuliana Lania, Tiziana Caramico, and Carmen Vitiello for assistance. We are grateful to the TIGEM Mutation Detection and to the TIGEM/IGB sequencing core facilities. This work was supported by the Italian Telethon Foundation and by the MURST-PRIN2002

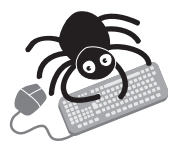

Supplementary table 1, showing primer sequences and PCR conditions, is available on the JMG website: http://www.jmedgenet.com/supplemental

\section{Authors' affiliations}

C Ziviello; S Banfi, Telethon Institute of Genetics and Medicine (TIGEM), Naples, Italy

C Ziviello, A Ciccodicola, Institute of Genetics and Biophysics "A Buzzati-Traverso", CNR, Naples

F Simonelli*, F Testa, E Rinaldi, Department of Ophthalmology, Second University of Naples, Naples

M Anastasi, Department of Ophthalmology, University of Palermo, Palermo, Italy

S B Marzoli, Neuro-ophthalmology Unit, University S Raffaele, Milan, Italy

B Falsini, Department of Ophthalmology, Universita' Cattolica del Sacro Cuore, Rome, Italy

D Ghiglione, Department of Ophthalmology, University of Genova, Genova, Italy 
C Macaluso, Department of Ophthalmology, University of Parma, Parma, Italy

M P Manitto, Department of Ophthalmology and Visual Science, University S Raffaele, Milan

C Garrè, Department of Oncology, Biology and Genetics, University of Genova, Genova

*The first two authors equally contributed to this work

Competing interests: none declared

Correspondence to: Dr Sandro Banfi, Telethon Institute of Genetics and Medicine (TIGEM), Via Pietro Castellino 111, 80131 Naples, Italy; banfi@tigem.it

Received 4 February 2005

Revised version received 1 March 2005

Accepted for publication 4 March 2005

\section{REFERENCES}

1 Pagon RA. Syndromic retinal dystrophy. In: Rinaldi E, eds. Retinitis pigmentosa: present knowledge and outlook. Naples: Liviana Medicina, 1993:151-66.

2 Gu S, Kumaramanickavel G, Srikumari CR, Denton MJ, Gal A. Autosomal recessive retinitis pigmentosa locus RP28 maps between D2S1337 and D2S286 on chromosome 2p11-p15 in an Indian family. J Med Genet 1999:36:705-7.

3 Bird AC. X-linked retinitis pigmentosa. Br J Ophthalmol 1975;59:177-99.

4 Weleber RG, Gregory-Evans K. Retinitis pigmentosa and allied disorders. In Ryan SJ, eds. Retina. St Louis: CV Mosby, 2001:362-470.

5 Boughman JA, Conneally PM, Nance WE. Population genetic studies of retinitis pigmentosa. Am J Hum Genet 1980;32:223-35.

6 Jay M. On the heredity of retinitis pigmentosa. $\mathrm{Br} J$ Ophthalmol 1982;66:405-16

7 Haim M. Retinitis pigmentosa: problems associated with genetic classification Clin Genet 1993;44:62-70.

8 Bunker CH, Berson EL, Bromley WC, Hayes RP, Roderick TH. Prevalence of retinitis pigmentosa in Maine. Am J Ophthalmol 1984;97:357-65.

9 Ayuso C, Garcia-Sandoval B, Najera C, Valverde D, Carballo M, Antinolo G. Retinitis pigmentosa in Spain. The Spanish Multicentric and Multidisciplinary Group for Research into Retinitis Pigmentosa. Clin Genet 1995:48:120-2.

10 Fossarello M, Serra A, Mansfield D, et al. Genetic and epidemiological study of autosomal dominant (ADRP) and autosomal recessive (ARRP) retinitis pigmentosa in Sardinia. In: Hollyfield JG, La Vail MM, Anderson RE, eds. Retinal degeneration. New York: Plenum Press, 1993:79-90.

11 Sohocki MM, Daiger SP, Bowne SJ, Rodriquez JA, Northrup H, Heckenlively JR, Birch DG, Mintz-Hittner H, Ruiz RS, Lewis RA, Saperstein DA, Sullivan LS. Prevalence of mutations causing retinitis pigmentosa and other inherited retinopathies. Hum Mutat 2001;17:42-51.

12 Inglehearn CF, Tarttelin EE, Plant C, Peacock RE, al-Maghtheh M, Vithana $E$, Bird AC, Bhattacharya SS. A linkage survey of 20 dominant retinitis pigmentosa families: frequencies of the nine known loci and evidence for further heterogeneity. J Med Genet 1998;35:1-5

13 Milla E, Maseras M, Martinez-Gimeno M, Gamundi MJ, Assaf H, Esmerado C Carballo M; Grupo Multicentrico Espanol de Retinosis Pigmentaria. Genetic and molecular characterization of 148 patients with autosomal dominant retinitis pigmentosa (ADRP). Arch Soc Esp Oftalmol 2002;77:481-4.

14 Miller SA, Dykes DD, Polesky HF. A simple salting out procedure for extracting DNA from human nucleated cells. Nucleic Acids Res 1988;16:1215.

15 Bowne SJ, Daiger SP, Hims MM, Sohocki MM, Malone KA, McKie AB, Heckenlively JR, Birch DG, Inglehearn CF, Bhattacharya SS, Bird A, Sullivan LS. Mutations in the RPI gene causing autosomal dominant retinitis pigmentosa. Hum Mol Genet 1999;8:2121-8.

16 Sohocki MM, Sullivan LS, Mintz-Hittner HA, Birch D, Heckenlively JR, Freund CL, Mclnnes RR, Daiger SP. A range of clinical phenotypes associated with mutations in CRX, a photoreceptor transcription-factor gene. Am J Hum Genet 1998;63:1307-15

17 Wada Y, Abe T, Takeshita T, Sato H, Yanashima K, Tamai M. Mutation of human retinal fascin gene (FSCN2) causes autosomal dominant retinitis pigmentosa. Invest Ophthalmol Vis Sci $2001 ; 42: 2395-400$.
18 Chakarova CF, Hims MM, Bolz H, Abu-Safieh L, Patel RJ, Papaioannou MG, Inglehearn CF, Keen TJ, Willis C, Moore AT, Rosenberg T, Webster AR, Bird AC, Gal A, Hunt D, Vithana EN, Bhattacharya SS. Mutations in HPRP3, a third member of pre-mRNA splicing factor genes, implicated in autosomal dominant retinitis pigmentosa. Hum Mol Genet 2002;11:87-92.

19 Dryja TP, Hahn LB, Cowley GS, McGee TL, Berson EL. Mutation spectrum of the rhodopsin gene among patients with autosomal dominant retinitis pigmentosa. Proc Natl Acad Sci USA 1991;88:9370-4.

20 Bowne SJ, Sullivan LS, Blanton SH, Cepko CL, Blackshaw S, Birch DG, Hughbanks-Wheaton D, Heckenlively JR, Daiger SP. Mutations in the inosine monophosphate dehydrogenase 1 gene (IMPDH1) cause the RP10 form of autosomal dominant retinitis pigmentosa. Hum Mol Genet 2002; 1 1:559-68.

21 Vithana EN, Abu-Safieh L, Pelosini L, Winchester E, Hornan D, Bird AC, Hunt DM, Bustin SA, Bhattacharya SS. Expression of PRPF31 mRNA in patients with autosomal dominant retinitis pigmentosa: a molecular clue for incomplete penetrance? Invest Ophthalmol Vis Sci 2003;44:4204-9.

22 Mears AJ, Kondo M, Swain PK, Takada Y, Bush RA, Saunders TL, Sieving PA, Swaroop A. Nrl is required for rod photoreceptor development. Nat Genet 2001;29:447-52

23 Rebello G, Ramesar R, Vorster A, Roberts L, Ehrenreich L, Oppon E, Gama D, Bardien S, Greenberg J, Bonapace G, Waheed A, Shah GN, Sly WS Apoptosis-inducing signal sequence mutation in carbonic anhydrase IV identified in patients with the RP17 form of retinitis pigmentosa. Proc Natl Acad Sci USA 2004;101:6617-22.

24 Keen TJ, Hims MM, McKie AB, Moore AT, Doran RM, Mackey DA, Mansfield DC, Mueller RF, Bhattacharya SS, Bird AC, Markham AF, Inglehearn CF. Mutations in a protein target of the Pim-1 kinase associated with the RP9 form of autosomal dominant retinitis pigmentosa. Eur $J$ Hum Genet 2002; 10:245-9.

25 Martinez-Gimeno M, Gamundi MJ, Hernan I, Maseras M, Milla E, Ayuso C, Garcia-Sandoval B, Beneyto M, Vilela C, Baiget M, Antinolo G, Carballo M. Mutations in the pre-mRNA splicing-factor genes PRPF3, PRPF8, and PRPF31 in Spanish families with autosomal dominant retinitis pigmentosa. Invest Ophthalmol Vis Sci 2003:44:2171-7.

26 Daiger SP, McGuire RE, Sullivan LS, et al. Progress in positional cloning of RP10 (7q31.3), RP1 (8q11-q21), and VMD1 (8q24). In, La Vail MM, Hollyfield JG, Anderson RE, eds. Degenerative retinal diseases New York, Plenum Press, 1997:277-94.

27 Tzekov RT, Sohocki MM, Daiger SP, Birch DG. Visual phenotype in patients with Arg41Gln and ala196+1bp mutations in the CRX gene. Ophthalmic Genet 2000;21(2):89-99.

28 McKie AB, McHale JC, Keen TJ, Tarttelin EE, Goliath R, van Lith-Verhoeven JJ, Greenberg J, Ramesar RS, Hoyng CB, Cremers FP, Mackey DA, Bhattacharya SS, Bird AC, Markham AF, Inglehearn CF. Mutations in the premRNA splicing factor gene PRPC8 in autosomal dominant retinitis pigmentosa (RP13). Hum Mol Genet 2001;10:1555-62.

29 Baum L, Chan WM, Yeung KY, Lam DS, Kwok AK, Pang CP. RPI in Chinese: eight novel variants and evidence that truncation of the extreme $\mathrm{C}$-terminal does not cause retinitis pigmentosa. Hum Mutat 2001;17:436

30 Acar C, Mears AJ, Yashar BM, Maheshwary AS, Andreasson S, Baldi A, Sieving PA, lannaccone A, Musarella MA, Jacobson SG, Swaroop A. Mutation screening of patients with Leber congenital amaurosis or the enhanced S-cone syndrome reveals a lack of sequence variations in the NRL gene. Mol Vis 2003;9:14-17.

31 Bareil C, Hamel C, Pallares-Ruiz N, Arnaud B, Demaille J, Claustres M. Molecular analysis of the rhodopsin gene in southern France: identification of the first duplication responsible for retinitis pigmentosa, c.998999ins4. Ophthalmic Genet 1999;20:173-82.

32 Wada Y, Tamai M. Molecular genetic analysis for Japanese patients with autosomal dominant retinitis pigmentosa. Nippon Ganka Gakkai Zasshi 2003; 107:687-94.

33 Zhang X, Fu W, Pang CP, Yeung KY. Screening for point mutations in rhodopsin gene among one hundred Chinese patients with retinitis pigmentosa. Zhonghua Yi Xue Yi Chuan Xue Za Zhi 2002;19:463-6.

34 Dryja TP, McGee TL, Hahn LB, Cowley GS, Olsson JE, Reichel E, Sandberg MA, Berson EL. Mutations within the rhodopsin gene in patients with autosomal dominant retinitis pigmentosa. N Engl J Med 1990;323:1302-7.

35 Farrar GJ, Kenna P, Redmond R, McWilliam P, Bradley DG, Humphries MM, Sharp EM, Inglehearn CF, Bashir R, Jay $M$, et al. Autosomal dominant retinitis pigmentosa: absence of the rhodopsin proline $\rightarrow$ histidine substitution (codon 23) in pedigrees from Europe. Am J Hum Genet 1990;47:941-5. 